\title{
O movimento lógico-histórico enquanto perspectiva didática para o ensino de matemática
}

\author{
The logical - historical movement while didactic perspective for the \\ teaching of Mathematics
}

Maria do Carmo de Sousa ${ }^{1}$

\begin{abstract}
RESUMO
$\mathrm{O}$ artigo $^{2}$ tem como objetivo discutir a necessidade de se organizar o ensino de Matemática, a partir de situações desencadeadoras de aprendizagem, tanto na Educação Básica, quanto nos cursos de licenciatura de Matemática que priorizem o pensamento teórico dialético. Defende-se que, o movimento lógico-histórico pode se configurar enquanto perspectiva didática para o ensino de Matemática. Considera-se que, o histórico consiste no processo de mudança do objeto, nas etapas de seu surgimento e desenvolvimento. O lógico é o meio pelo qual o pensamento realiza esta tarefa no processo de reflexão sobre o histórico, de forma que o lógico reflete os principais períodos da história do objeto. Pressupõe-se que, alunos da Educação Básica, licenciandos e professores que ensinam Matemática ao terem acesso aos nexos conceituais (internos e externos) dos conteúdos matemáticos presentes na História da Matemática e em diversas historiografias da Matemática podem se apropriar da unidade dialética teoria-prática e compreender a realidade fluente, na qual estamos inseridos.
\end{abstract}

Palavras-chave: Pensamento teórico dialético. Historiografia da matemática. História da matemática. Nexos conceituais. Situação desencadeadora de aprendizagem.

\begin{abstract}
The article aims to discuss the need to organize the teaching of mathematics, from outburst situations of learning both in basic education, as in mathematics degree courses that prioritize theoretical dialectical thinking. Stands up that the logical-historical movement can be configured as didactic perspective to the teaching of Mathematics. It is considered that the history is the object of the change process, the stages of its emergence and development. The logic is the means by which thought accomplishes this task in the process of reflection on the history, so that the logical reflects key periods in the history of the object. It is assumed that, Basic Education students, undergraduates and teachers who teach Mathematics to have access to the conceptual links (internal and external ) of the mathematical content present in the History of Mathematics and several historiography of mathematics can appropriate the theorypractice dialectic unity and understand fluent reality in which we operate.
\end{abstract}

Keywords: Dialectical theoretical thinking. Historiography of mathematics. History of mathematics. Conceptual links. Outburst learning situation.

\footnotetext{
${ }_{1}^{1}$ Departamento de Metodologia de Ensino (DME). Universidade Federal de São Carlos (UFSCar). E-mail:mdcsousa@ufscar.br.

${ }^{2}$ É produto de uma investigação desenvolvida no âmbito do Programa Observatório da Educação (OBEDUC), a qual contou com apoio financeiro do INEP/Capes.
} 


\section{Introdução}

Ao analisarmos o ensino atual de Matemática, no Brasil, a partir da perspectiva histórico-cultural, podemos afirmar que, apesar de várias mudanças que vêm sendo propostas pelos pesquisadores da área da Educação Matemática, nas últimas décadas, especialmente, no campo da Didática, a organização da maioria das aulas de Matemática, ministradas tanto na Educação Básica, quanto nos cursos de licenciatura de Matemática, tem priorizado o treinamento (Lima, 1998), uma vez que: 1) Em um primeiro momento, o professor mostra o conceito aos alunos; 2) Em seguida, demonstra o funcionamento deste conceito; 3) Depois, através de listas de exercícios, treina os alunos para que aprendam o conceito e 4) Por último, avalia através de provas se, os alunos aprenderam o conceito.

Podemos afirmar que, esse tipo de organização de ensino, praticamente obriga, a maioria dos alunos das escolas da Educação Básica e dos cursos de licenciatura de Matemática a ficar sentados e enfileirados, durante horas, primeiramente, copiando o que os professores expõem na lousa e, em seguida, treinando o que copiaram para serem avaliados. É um ciclo vicioso que tem frequentado as escolas e as universidades, há muito tempo.

Isso quer dizer que, durante anos, os alunos entram e saem das aulas de Matemática com a sensação de que, os conceitos matemáticos são fragmentados, não possuem história. Quando muitos destes alunos se tornam professores de Matemática, afirmam, com certa razão que, teoria e prática não se relacionam.

Essa forma de organizar o ensino de Matemática, através de cópias, treinos de longas listas de exercícios, da memorização e da fragmentação dos conceitos está fundamentada, segundo Davydov (1982), nos pressupostos da didática tradicional, uma vez que, este tipo de organização não considera os nexos conceituais (internos e externos) que se apresentam nos conceitos matemáticos, porque prioriza o pensamento empírico, ou ainda, o estudo dos elementos perceptíveis destes conceitos. Aqui, os nexos externos dos conceitos matemáticos estão relacionados à linguagem formal porque estão limpos, despidos de contradições, de práticas culturais e sociais presentes na história dos conceitos. 
Os nexos externos são explicitados na sala de aula completamente desconectados das diversas áreas do conhecimento a partir do aspecto simbólico. É como se os símbolos tivessem vida própria; falassem por si só. Prioriza-se a forma dos conceitos. Forma e conteúdo estão desconectados.

Há de se chamar atenção para o fato de que, na didática tradicional não se considera que os conceitos estudados são gerados, em sua maioria na praxis humana. Esquece-se que a atividade humana está contextualizada em "um particular contexto histórico, cultural e institucional” (Renshaw, 1999, p. 10). Nesse sentido, os conteúdos contêm nexos internos e externos. É por este motivo que, concordamos com Libâneo (2004) quando afirma que:

(...) a didática precisa incorporar as investigações mais recentes sobre modos de aprender e ensinar e sobre o papel mediador do professor na preparação dos alunos para o pensar. Mais precisamente, será fundamental entender que o conhecimento supõe o desenvolvimento do pensamento e que desenvolver o pensamento supõe metodologia e procedimentos sistemáticos do pensar. Nesse caso, a característica mais destacada do trabalho do professor é a mediação docente pela qual ele se põe entre o aluno e o conhecimento para possibilitar as condições e os meios de aprendizagem, ou seja, as mediações cognitivas. (LIBÂNEO, 2004, p. 06).

Assim, para se aperfeiçoar a instrução e entrar em consonância com os conhecimentos científico-técnicos deste século, de forma a mudar o tipo de pensar que está projetado tanto nas escolas, quanto nos cursos de licenciaturas de Matemática, concordamos com Davydov (1982) que, o pensamento teórico, dialético, pode ser considerado uma possibilidade de mudança, considerando-se que:

É na relação dialética entre a atividade e a comunicação que se estabelece o vínculo professor-estudante, estudante-estudante, estudante-conhecimento, estudante-vivência, estudante-prática concreta. Nesta rede de vínculos se vai estruturando a personalidade. Vai tendo lugar na instituição educativa uma parte importante do crescimento dos seres humanos. (FERNÁNDEZ, 2007, p. 12).

Aqui, há de se levar em conta que:

Parte-se, então, que a didática é uma teoria prática, se aceita o caráter e natureza dos problemas que enfrenta, uma vez que sua principal realização teórica é o desenvolvimento dos princípios acerca da contextualização e intercomunicação entre as teorias e 
deste modo poder evitar um dogmatismo metodológico. (Fernández, 2007, p. 03).

Ao assumirmos que o pensamento teórico dialético deve fazer parte da organização do ensino de Matemática, quer nas escolas da Educação Básica, quer nos cursos de licenciatura de Matemática, estamos defendendo que:

O estudante deve aprender a contextualizar histórica e socialmente sua atividade profissional, perguntando-se pelo significado social dos conteúdos que transmite e dos métodos e formas que usa dentro do conjunto das relações sociais vigentes. Isto significa situar os fenômenos do ponto de vista de seu desenvolvimento histórico-classista. (FERNÁNDEZ, 2007, p. 04).

Neste contexto, os futuros professores dos cursos de licenciatura de Matemática e, consequentemente, os alunos da Educação Básica passam a ter contato com outro tipo de organização de ensino de Matemática, muito diferente daquele que promove o treinamento e a fragmentação dos conceitos matemáticos, em seu último estágio de rigor.

Mas, como organizar o ensino de Matemática, considerando־se o pensamento teórico dialético, de forma a romper com a didática tradicional?

Essa foi uma das questões que conduziu a investigação, de cunho participante, de caráter longitudinal e qualitativo intitulada: Produtos Educacionais no Mestrado Profissional em ensino de Física e Matemática: itinerários de desenvolvimento, implementação e avaliação, a partir da rede de pesquisa participante escola-universidade, desenvolvida no período de janeiro de 2009 a dezembro de 2012, no âmbito do Programa Observatório da Educação OBEDUC (INEP/Capes), a qual teve como um dos objetivos, elaborar situações desencadeadoras de aprendizagem (Moura, 2010), fundamentadas no movimento lógico-histórico e com foco no pensamento teórico dialético, para se ensinar os conceitos matemáticos, na Educação Básica.

Assim, neste artigo, inicialmente, apresentaremos os pressupostos teóricos do que vem a ser o movimento dialético lógico-histórico. Em seguida, a relação deste movimento com os conceitos matemáticos. No terceiro item, indicaremos, como o movimento lógico-histórico se configurou enquanto perspectiva didática para o ensino de Matemática, bem como os elementos metodológicos que 
fundamentaram a investigação. Por último, com o intuito de responder a questão de pesquisa, exemplificaremos, a partir da Dissertação de Mestrado de Borges (2011), como a professora-pesquisadora organizou o ensino de sua sala de aula, a partir do desenvolvimento de situações desencadeadoras de aprendizagem que consideram o movimento lógico-histórico da álgebra.

\section{0 movimento lógico-histórico: pressupostos teóricos}

Conforme anunciamos anteriormente, neste item, temos como intenção apresentar a definição mais geral do que vem a ser o movimento lógico-histórico, estudado por Kopnin (1978) enquanto uma das formas de pensamento elaborada pelos homens.

Os elementos constitutivos do lógico-histórico estão diretamente relacionados aos conceitos de: totalidade, realidade, praxis, movimento, fluência, interdependência, mutabilidade, imutabilidade, momentos de permanência, relatividade, lógica, história, processo, conhecimento e pensamento; e das categorias: concreto e abstrato, conceito, juízo e dedução estudados por Kopnin (1978) e Kosik (2002) e, se fundamentam na teoria materialista dialética do conhecimento.

Ao estudarmos esses elementos, percebemos que o movimento lógicohistórico do pensamento humano, há algum tempo é objeto de estudo de filósofos, matemáticos, psicólogos e por que não dizer, de todos aqueles que de alguma forma se preocupam com o conhecimento e com o como o homem entende, em sua subjetividade, tudo aquilo que apreende (KOPNIN, 1978; BOHM, 1980; KOSIK, 2002) da realidade que contém leis objetivas, elaboradas no ato da atividade cognitiva de si próprio.

Segundo Kopnin (1978, p. 53), "uma vez apreendidas, as leis do mundo objetivo se convertem em leis do pensamento, e todas as leis do pensamento são leis representadas do mundo objetivo".

Dessa forma, "o mundo objetivo e suas leis interessam ao homem, não por si mesmos, mas enquanto meio de satisfação de determinadas necessidades sociais" (KOPNIN, 1978, p. 61). Por isso mesmo, as leis são mutáveis quanto às 
necessidades sociais. Não são leis como entende a metafísica, algo determinista e imanente ao ser.

O pensamento humano busca formas que possibilitem a transformação contínua da realidade através de seu trabalho físico e intelectual durante a sua pequena trajetória ou viagem no universo, trajetória que designamos pelo nome de vida.

Dessa forma, entender o lógico-histórico da vida significa compreender a relação existente entre a mutabilidade e a imutabilidade das coisas; a relatividade existente entre o pensamento humano e a realidade da vida, bem como compreender que tanto o lógico quanto o histórico da vida estão inseridos na lei universal, que é o movimento.

Compreender o movimento lógico-histórico da vida é compreender que todo conhecimento contém angústias, medos, aflições, ousadias, inesperados, novas qualidades, conflitos entre o velho e o novo, entre o passado e o futuro. É compreender que a totalidade do conhecimento é o próprio movimento da realidade objetiva que sempre estará por vir a ser.

Para Kopnin (1978), a totalidade do objeto está nos pares dialéticos, enquanto para Davydov (1982), tal totalidade está nos nexos internos e externos do conceito e defendemos que a totalidade está presente na confluência entre o lógico-histórico, pois tal confluência conecta o singular à totalidade, os nexos internos aos nexos externos do conceito.

Trata-se de um movimento fluente (BOHM, 1980) que nos auxilia a construir a realidade que nos propomos a ver.

Para tanto, consideramos o pressuposto de que a representação do histórico pelo lógico, a reprodução do substancial, do movimento do vir a ser do objeto, da história de sua formação e desenvolvimento se realiza nas diversas formas de movimento do pensamento (KOPNIN, 1978).

Definido que a forma do pensamento pode ser entendida "como modo de representação da realidade por meio de abstrações" constituindo-se certos "elos do movimento no sentido da realidade objetiva", entendemos que "os resultados do conhecimento", possibilitam-nos chegar à conclusão que durante o "processo da 
eterna e infinita aproximação do pensamento ao objeto, estabelecem-se certos laços nos quais se refletem os resultados do conhecimento do objeto" (Kopnin,1978, p. 187) e esses laços são justamente as formas de pensamento.

Há de se considerar nesta análise duas características essenciais que compõem a realidade, no seu sentido pleno, quando esforçamo-nos para compreendê-la: a interdependência e a fluência (CARAÇA, 1998).

O conceito de interdependência está associado às relações entre as coisas. Toda a "realidade em que estamos mergulhados é um organismo vivo, uno, cujos compartimentos se comunicam e participam, todos, da vida uns dos outros" (CARAÇA, 1998, p. 103).

Na fluência, constata-se que "o Mundo está em permanente evolução; todas as coisas, a todo o momento, se transformam, tudo flui, tudo dévem", afirmação já feita por Heráclito de Éfeso num tempo onde se acreditava na imutabilidade do mundo, porque tudo estava fixo, pronto, acabado, determinado, inclusive a verdade. O conceito de fluência "pode ser verificado por qualquer um de nós, seja qual for aquele objeto em que fixemos a nossa atenção. Não é verdade que tudo está sujeito a uma mesma lei de nascimento, vida e morte, que por sua vez vai originar outros nascimentos?" (CARAÇA, 1998, p. 103).

A realidade é um processo; algo em movimento, ampla e pode se manifestar por categorias, sendo uma delas a realidade objetiva (CARAÇA, 1998; BOHM, 1980; KOSIK, 2002 E KOPNIN, 1978).

A realidade objetiva contém os reflexos dos resultados do conhecimento do objeto, que decorrem do movimento, da fluência, da interdependência, do pensamento humano. É o mundo das sensações elaborado pela praxis humana, abstraído e logicamente formalizado pelo pensamento em conceitos. Contém a verdade elaborada pelos homens. Tal realidade, ao ser pensada e elaborada, considera os nexos internos e externos presentes no movimento lógico-histórico do pensamento humano.

A realidade objetiva decorre, assim, do movimento lógico-histórico que o pensamento faz sobre a realidade.

Assim: 
O lógico reflete não só a história do próprio objeto como também a história do seu conhecimento. Daí a unidade entre o lógico e o histórico, ser premissa necessária para a compreensão do processo de movimento do pensamento, da criação da teoria científica. À base do conhecimento dialético do histórico e do lógico resolve-se o problema da correlação entre o pensamento individual e o social; em seu desenvolvimento intelectual individual o homem repete em forma resumida toda a história do pensamento humano. A unidade entre o lógico e o histórico é premissa metodológica indispensável na solução de problemas de inter-relação do conhecimento e da estrutura do objeto e conhecimento da história de seu desenvolvimento. (KOPNIN, 1978, p.186).

Ao considerarmos a unidade dialética apresentada no par lógico-histórico do movimento do pensamento, defendemos que esse movimento, durante toda a sua existência procura se aproximar do movimento que compõe o objeto em estudo.

Essa composição é individual e coletiva. É histórica e lógica. Construindose no dia-a-dia das mais diversas civilizações. Todo objeto do conhecimento humano, em seu desenvolvimento, contém, necessariamente, a unidade dialética lógica-história.

Em termos de (re)criação do conceito científico no indivíduo consideramos que a própria construção da lógica do objeto, contém uma história, embora haja uma tendência em desconsiderar esta composição do apreender humano.

Ao nos aproximarmos para conhecer o todo que contém e está contido nos objetos, o foco do conhecimento deixa de ser o aspecto linear da história, enquanto sucessão de fatos e passa a ser o substancial, que é na verdade, a mutabilidade da história dos objetos contida e que contém uma realidade indivisível em constante movimento.

O cerne dessa realidade é a fluência, o movimento, a transformação, e não a fragmentação do próprio pensar humano que contém a interdependência, característica fundamental do movimento do pensamento.

Ao tomarmos consciência do movimento do pensamento enquanto algo responsável pela compreensão e apreensão do objeto, faz-se necessário "entender a natureza da realidade, em geral, e a da consciência, em particular, como um todo coerente, o qual nunca é estático ou complexo, mas um processo infindável 
de movimento e desdobramento. O próprio pensamento encontra-se num processo efetivo de movimento" (BOHM, 1980, p. 09).

Quando o foco da discussão envolve pensar ou ainda eleger e analisar os principais aspectos que se apresentam e fundamentam a representação do histórico pelo lógico, assim como a história de sua formação e desenvolvimento realizada nas diversas formas do pensamento, não queremos nos esquivar, muito menos ignorar, as questões decorrentes do pensar a realidade, a partir da totalidade e não da fragmentação.

A totalidade está relacionada às nossas reflexões e ponderações "sobre a natureza do movimento, tanto no pensamento quanto no objeto do pensamento" (BOHM, 1980, p. 10).

Ao pensarmos em alguma coisa, essa coisa parece "ser apreendida como algo estático, ou então como uma série de imagens estáticas. No entanto, na experiência efetiva do movimento, sente-se um processo de fluxo ininterrupto e indiviso, ao qual se relaciona a série de imagens estáticas no pensamento, como uma sequência de fotografias ('paradas') que poderiam estar relacionadas à realidade de um carro em movimento", questão que já foi levantada filosoficamente por Zenão e até hoje está sem solução satisfatória (BOHM, 1980, p. 09).

Ora, é difícil desconsiderar, durante a apreensão do objeto, para tentar estudá-lo, a lei universal, a lei do movimento, a lei da fluência e a lei da interdependência, embora, ao tentar compreender, cientificamente, aspectos que compõem o desenvolvimento do objeto, da coisa em estudo, o pensamento humano insista e necessite pensar de forma fragmentada, a partir de isolados (CARAÇA, 1998).

Mas, como relacionar o movimento lógico-histórico com os conceitos matemáticos?

É sobre esta questão que trataremos no próximo item. 


\section{Relações entre o movimento lógico-histórico e os conceitos matemáticos}

Davydov (1982, p. 296-7) define o pensamento como "uma atividade espiritual muito complexa" onde a "formação de representações sensoriais gerais, diretamente entrelaçadas com a atividade prática cria as condições" para que a atividade se desenvolva.

Nesse sentido, "o pensamento de um homem é o movimento das formas de atividade da sociedade historicamente constituídas e apropriadas por aquele" (DAVYDOV, 1982, p. 279). O pensamento teórico contém os nexos internos, o movimento lógico-histórico do objeto estudado. Por este motivo, pode ser denominado de pensamento teórico dialético.

Aqui, como em Kopnin (1978), o termo objeto, tem a conotação de ato de conhecimento e as leis dos seus movimentos. Os nexos internos dos objetos estudados só se realizam em movimento.

Quando se trata do campo da didática, Davydov (1982) sugere que esta se preocupe com o como possibilitar aos alunos a construção do pensamento teórico, na sala de aula. Para tanto é preciso se preocupar com os nexos internos do conceito. Critica a didática tradicional que ao considerar a psicologia tradicional se propõe a desenvolver nos alunos, dos diversos níveis de ensino, o pensamento teórico a partir do pensamento empírico-discursivo.

O pensamento empírico-discursivo considera apenas o estudo dos aspectos externos do objeto estudado. Como exemplo, cita o estudo de ângulos feito com base na didática tradicional, na maioria das escolas.

De forma geral, o estudo do conceito de ângulo é feito a partir de algumas manipulações geométricas e algébricas que desconsideram o conceito de movimento. Durante a organização do ensino, os professores, orientados pelos autores de livros didáticos, priorizam a partir do pensamento empíricodiscursivo, algumas relações que podem ser estabelecidas entre a linguagem do cotidiano e a figura padronizada. É como se a figura tivesse vida própria e falasse por si mesma. 
Nesse sentido, o simples fato de classificarmos os ângulos em reto, agudo e obtuso, na sala de aula, a partir de elementos angulares de objetos, seja da vida diária, sejam aqueles construídos pela criança ou ainda, a partir da observação da natureza não garante o entendimento profundo e complexo do conceito de ângulo. Há o esquecimento de se considerar o conceito de movimento que, por sua vez, a abordagem lógico-histórica desse conceito abrange.

Os nexos conceituais do ângulo não se estabelecem por apenas uma representação estática: o desenho, seja essa representação gráfica, seja nos objetos, mas, sobretudo pelo estudo das relações do movimento dos corpos.

Qualquer corpo em movimento em relação ao outro requer necessidade ou sugere a formação de ângulos. Assim, é a terra em relação ao sol. O ângulo aparece como resultado do movimento relativo desses dois corpos celestes.

Para Kopnin (1978, p. 24) "a passagem do nível empírico ao teórico não é uma simples transferência de conhecimento da linguagem cotidiana para a científica, mas uma mudança de conteúdo e forma do conhecimento". No caso específico do conceito de ângulo, a generalização é possível quando se inclui o estudo dos movimentos relativos dos corpos celestes.

Tanto Caraça (1998), quanto Davydov (1982), Kopnin (1978) e Kosík (2002) falam de certo movimento, de certa fluência que se apresenta na construção do conhecimento humano. Tal movimento ou fluência compõe a natureza do pensar científico, portanto, compõe a natureza do pensar matemático.

Davydov (1982) e Kopnin (1978) falam de nexos internos que se apresentam no pensamento teórico. Os nexos internos são diferentes dos nexos externos.

Os nexos externos se limitam aos elementos perceptíveis do conceito enquanto os internos compõem o movimento lógico-histórico do conceito. Os nexos externos ficam por conta da linguagem. São formais. Exemplo disso é a classificação dos ângulos em retos, agudos, obtusos.

Os nexos conceituais, ou seja, os elos que fundamentam os conceitos contêm a lógica, a história, as abstrações, as formalizações do pensar humano no processo de constituir-se humano pelo conhecimento. 
Definimos nexo conceitual como o elo entre as formas de pensar o conceito, que não coincidem, necessariamente, com as diferentes linguagens que representam o conceito matemático.

Os nexos internos do conceito mobilizam mais o movimento do aluno do que os nexos externos. Os nexos externos não deixam de ser uma linguagem de comunicação do conceito apresentada em seu estado formal, mas que não necessariamente denotam sua história. Dão pouca mobilidade ao sujeito para elaborar o conceito.

Ensinar e organizar o ensino de Matemática, a partir dos nexos externos, traz resultados parciais ao aluno. Os prejuízos podem ser comprovados não só na falta da subjetividade do sujeito, enquanto aprende, como também na formação do pensamento teórico. O pensamento teórico generaliza o conceito. Prova disso é aprender o conceito de variável só a partir da incógnita.

Entendemos que a conexão entre os nexos conceituais da álgebra, por exemplo: fluência, campo de variação e variável forma o conceito de álgebra promove o pensamento teórico dialético da álgebra que deveria ser ensinada na Educação Básica.

Aprender a variação dentro de limites, conjuntos, fronteiras, condições definidas, significa relativizar a variação, criar dependências, criar a partir da variável, ampliar o conceito de variável para o conceito de função.

No caso da álgebra simbólica ${ }^{3}$ os nexos conceituais não precisam coincidir com as linguagens retórica, sincopada, geométrica e simbólica, ou seja, com a álgebra não simbólica ${ }^{4}$, pois vão além destas, incluem os conceitos de fluência, de relatividade, campo de variação e o conceito de variável.

Mesmo porque a linguagem é o momento estático do pensamento, enquanto que as formas de pensamento se sobrepõem à linguagem. Não há como fazer categorias do pensamento da mesma forma que categorizamos a linguagem.

\footnotetext{
3 Álgebra simbólica é um dos estágios da álgebra que Smith (1958) estudou. Representa-se, de forma geral, a variável por letras do alfabeto.

${ }^{4}$ Álgebra não simbólica: É composta por três estágios ou fases: retórica, geométrica e sincopada. $\mathrm{Na}$ álgebra retórica a variável é representada por uma palavra. No caso da álgebra geométrica, a variável é representada a partir de segmento de reta. Já, na álgebra sincopada, a variável é representada, a partir da abreviação de palavras (SMITH, 1958; BOYER, 1974; RÍBNIKOV, 1987; PARADÍS \& MALET, 1989; USISKIN, 1995; EVES, 1997; CARAÇA, 1998; FRAILE, 1998).
} 
A linguagem alimenta o pensamento. Os nexos conceituais alimentam as premissas. As premissas alimentam o conhecimento científico. Os nexos conceituais são lógico-históricos e se apresentam no movimento do pensamento, tanto daquele que ensina, quanto daquele que aprende.

Temos como pressuposto que os nexos internos dos conceitos que ensinamos estão presentes a todo o momento na sala de aula.

As abstrações que se processam nesse movimento devem se manifestar quando ensinamos e aprendemos os conceitos matemáticos. Se o conteúdo é a álgebra, faz-se necessário entender o movimento que se processa no pensamento, enquanto estudamos e aprendemos álgebra.

Kopnin (1978), ao estudar o pensamento teórico e suas relações com os nexos internos do objeto, diz que o movimento do pensamento é histórico e lógico. O lógico está isento das casualidades do histórico e Kosík (2002, p. 60) afirma que "a investigação lógica mostra onde começa o histórico, e o histórico completa e pressupõe o lógico".

Para melhor entendermos tais relações há de se considerar ainda o conceito de conceito.

Kopnin (1978, p. 195-196) define o conceito como a confluência entre o lógico e o histórico, o qual contém inúmeras abstrações elaboradas pela humanidade, de tempos em tempos ou ainda como "um juízo, cujo predicado é a ideia universal do fenômeno" e o juízo, por estar presente em toda abstração, é definido como "as formas mais simples e mais importantes de abstração, que constitui simultaneamente o traço característico de todo processo de pensamento" (KOPNIN, 1978, p. 195-6).

Assim, defendemos que seja possível elaborar o conceito de álgebra na sala de aula, por professores e alunos, à medida que os envolvidos tiverem a possibilidade de construir juízos sobre os nexos conceituais da álgebra, para poderem compreender a confluência existente entre o movimento lógico-histórico, ou ainda entre as classes da álgebra que constituem o lógico do histórico da formação de sua linguagem formal, do movimento do pensamento algébrico, embora os diversos matemáticos, teóricos, estudiosos tenham definido, formalmente, o que vem a ser álgebra. 
Para tanto, entendemos que o caminho a ser percorrido deverá ser aquele onde se considera a relação lógico-histórica do número, da figura e da letra. Esse caminho contém a fluência dos nexos conceituais (internos e externos) que compõem o conceito de variável.

Pensar sobre os nexos conceituais na sala de aula é possível quando nos propomos a desenvolver situações desencadeadoras de aprendizagem com futuros professores do curso de Matemática e com alunos da Educação Básica que lhes proporcionem reflexões sobre os nexos conceituais dos conteúdos matemáticos, dentre eles, os algébricos.

Para tanto, consideramos que todo professor organiza o ensino de Matemática, na sala de aula, a partir da concepção que tem sobre os conteúdos que ensina.

Defendemos que, quando nós, professores de Matemática, selecionarmos situações desencadeadoras de aprendizagem para as nossas aulas, deveríamos almejar que estas proporcionem aos alunos, a possibilidade de compreender o mundo que nos cerca, a partir do momento em que as abstrações forem se constituindo em conteúdo concreto para o pensamento. Ou seja, deveríamos considerar o pensamento teórico dialético, nas salas de aula, tanto da Educação Básica, quanto nos cursos de licenciatura de Matemática.

Nesse sentido, há de se considerar ainda que, tanto Kopnin (1978), quanto Davydov (1982) consideram o concreto e abstrato enquanto categorias essenciais para a elaboração do pensamento teórico.

O concreto, segundo Kosik (2002) "se torna compreensível através da mediação do abstrato, o todo através da mediação da parte” (KOSÍK, 2002, p. 36).

Por concreto, também, "se entende o objeto solto sensorialmente perceptível ou sua imagem gráfica e, por abstrato, as reiteradas e similares propriedades soltas de um conjunto de objetos, mentalmente separadas dos mesmos e consideradas independentemente" (DAVYDOV, 1982, p. 332).

Ao fazermos abstrações, podemos falar das propriedades gerais do objeto e até separá-las mentalmente de outras propriedades, ao mesmo tempo em que 
podemos operar com as propriedades abstraídas das representações dos objetos estudados.

O conteúdo das abstrações referido pelo autor não têm existência na realidade. Não há como negar a total fragmentação desse movimento, o de operar com abstrações, a partir de suas propriedades, totalmente desvinculadas do objeto estudado.

Na mesma linha de raciocínio, segue Kopnin (1978, p. 154), ao afirmar que o abstrato é a "separação, o isolamento de alguma propriedade sensorialmente acessível do objeto", porém, "a tarefa da abstração não é separar uns dos outros indícios sensorialmente perceptíveis, mas através deles descobrir novos aspectos no objeto, que traduzam as relações de essência5" (KOPNIN, 1978, p. 161).

O concreto no pensamento, para Kopnin (1978, p. 162) "se manifesta como forma superior do conhecimento concreto". É a unidade do diverso. Não é a soma mecânica de abstrações isoladas. "O concreto é o ponto de partida e chegada do conhecimento" (1978, p. 157).

É “o conhecimento mais profundo e substancial dos fenômenos da realidade, pois reflete com o seu conteúdo não as definibilidades exteriores do objeto em sua relação imediata, acessível à contemplação viva, mas diversos aspectos substanciais, conexões, relações em sua vinculação interna necessária. Abstrações isoladas elevam o nosso conhecimento da apreensão do geral empírico ao universal, enquanto o concreto no pensamento, fundamenta a conexão do singular com o universal, fornece não uma simples unidade de aspectos diversos, mas a identidade dos contrários". (KOPNIN, 1978, p. 162)

Kopnin (1978) e Kosik (2002) rompem com a ideia de que o movimento do conhecimento teórico ocorre a partir da transição do concreto manipulável ao abstrato, do pensamento empírico-discursivo ao pensamento teórico. Rompem com a visão empírica do pensamento, que considera o estudo do isolamento das propriedades que compõem o pensar humano. Afirmam que o conhecimento contém definibilidades conceituais decorrentes de conexões internas e não apenas definibilidades exteriores do objeto.

\footnotetext{
${ }^{5}$ Em nossos estudos os termos cerne, substância e substancial representam a essência de que fala Kopnin (1978).
} 
Quando o objeto é a álgebra simbólica afirmamos que o conhecimento mais profundo e substancial desta reflete não as definibilidades exteriores da variávelletra em sua relação imediata, acessível à contemplação viva, mas diversos aspectos substanciais, conexões, relações em sua vinculação interna com os conceitos de número, movimento e aspectos geométricos.

$\mathrm{O}$ abstrato e o concreto refletem a mudança da imagem cognitiva tanto no que concerne à multilateralidade da abrangência do conceito quanto à sua profundidade, a penetração em sua substância, em seu movimento. Expressam as leis da mudança que se opera no conteúdo do conhecimento, ao longo de seu desenvolvimento.

Exemplo disso seria o abstrato e o concreto do movimento lógico-histórico da variável.

O abstrato e o concreto do movimento lógico-histórico da variável refletem a mudança da imagem cognitiva, no que diz respeito à multilateralidade da abrangência do conceito de álgebra quanto à sua profundidade, à penetração em sua substância, em seu vir a ser, em seu movimento.

O movimento que vai do concreto ao abstrato, da álgebra, considera a transição do conceito de número como perda da concreticidade e da substancialidade de seus nexos internos, o fazer corresponder e o valor posicional, por exemplo, ao mesmo tempo em que o processo do abstrato ao concreto considera a totalidade concreta do número que se constitui a partir dos mesmos nexos internos, o fazer corresponder e o valor posicional, por exemplo, na qual se reproduz idealmente a realidade em todos os seus planos e dimensões, a partir do conceito de variável que se materializa no conceito de função.

O fato é que o concreto e o abstrato do conceito de número constituem os campos de variação. Não é possível falar em função, sem, necessariamente, considerar os campos de variação. Nesse caso, a concreticidade do número não está nos elementos perceptíveis do numeral, por exemplo, na fração que representa metades, terços, quartos etc e sim nos conjuntos numéricos: Naturais $(\mathrm{N})$, Inteiros (Z), Racionais (Q), Irracionais (I) ou Reais (R). 
Nesse sentido, a formação do pensamento algébrico no aluno da Educação Básica não pode se limitar como se fosse uma transposição de linguagens do todo caótico. Exemplo dessa transposição aparece em frases do tipo: o $x$ pode ser qualquer coisa, ou ainda, um número natural, uma fração, um número inteiro. Aqui, o aluno tem a impressão de que a letra $x$ fala por si. No entanto, fica sem compreender, por exemplo, que: 1) a variável letra pode assumir alguns papéis, como: incógnita, parâmetro ou variável. Tais papéis estão atrelados aos movimentos da vida que podem ser expressos na forma de equação, inequação ou função. 2) a variável, antes de ser representada pela letra, já foi representada por palavras (álgebra retórica), segmento de reta (álgebra geométrica) e palavras abreviadas (álgebra sincopada). Ou seja, a álgebra simbólica é síntese da álgebra não simbólica. Logo, a variável letra pode ser compreendida enquanto síntese da palavra, da figura, do numeral e da letra (SOUSA, 2004; 2009).

Defendemos que, o concreto da álgebra se torna compreensível através de seus nexos internos e externos.

Assim, a possibilidade de generalização da álgebra poderá ocorrer quando houver um conhecimento profundo do conceito de variável, de forma que o movimento do pensamento do indivíduo o torne autônomo. Para tanto, o estudo do conceito mais geral de variável, nas salas de aula, deveria considerar a palavra, a figura, o numeral e a letra.

O todo seria a álgebra que está por vir a ser e as partes, a álgebra não simbólica: retórica, sincopada e geométrica e, a álgebra simbólica. O concreto do conteúdo algébrico se torna compreensível através da mediação das abstrações contidas nos conceitos de número, figura, palavra e letra, enquanto o todo da álgebra se torna compreensível através da mediação da álgebra não simbólica e da álgebra simbólica.

Exemplo disso seria o estudo dos conceitos abstratos:

1) De permanência e fluência;

2) De campos numéricos: naturais, inteiros, racionais, irracionais e reais;

3) Da variável: variável-palavra, variável-figura, variável-numeral e variável-letra que compõem o concreto da álgebra. 
Os pressupostos que estamos considerando fazem-nos concordar com Davydov (1982) e Kopnin (1978) quando afirmam que o pensamento teórico se configura a partir de nexos internos dos conceitos e leis de movimento interdependentes, pois o pensamento teórico:

\begin{abstract}
Reflete o objeto no aspecto das relações internas e leis do movimento deste, cognoscíveis por meio da elaboração racional dos dados do conhecimento empírico. Sua forma lógica é constituída pelo sistema de abstrações que explica o objeto. A aplicação prática do conhecimento teórico é quase ilimitada, enquanto no sentido científico, a construção da teoria se manifesta como um resultado final, como conclusão do processo do conhecimento. (KOPNIN, 1978, p. 152).
\end{abstract}

Nesse sentido, as abstrações e leis do movimento do pensamento, ao se constituir em sua forma lógica e teórica, consideram os aspectos lógicos, históricos e formais do objeto a ser estudado.

\title{
4 Configurando o movimento lógico-histórico enquanto perspectiva didática para o ensino de Matemática
}

A História da Matemática "é a ciência das leis objetivas do desenvolvimento da Matemática” (RÍBNIKOV, 1987, p. 10). Explica a natureza da Matemática. Explica o desenvolvimento do pensar matemático, a partir de diversos pontos de vista, ou seja, a partir de diversas historiografias. Dessa forma, nos permitimos ter dúvidas sobre as verdades matemáticas. E, ensinar e aprender Matemática não seria isso? Ter oportunidades de refletir sobre as diversas interpretações que fundamentam os conceitos matemáticos?

Ao estudarmos a História da Matemática e suas versões historiográficas, podemos perceber que as relações quantitativas e formas espaciais têm relações indissolúveis com as exigências da técnica e as ciências naturais.

Ao mesmo tempo, podemos nos conscientizar, a partir de inúmeros exemplos, de que suas verdades não foram construídas num processo harmonioso de “desenvolvimento contínuo e gradual”. O desenvolvimento da História da Matemática se dá através de uma luta "enfurecida do novo contra o velho", onde a "luta se revela particularmente forte quando o novo irresistivelmente vence, 
apesar dos fracassos", incluindo-se "a morte dos criadores da ciência" (RÍBNIKOV, 1987, p. 15).

Conhecer a história do desenvolvimento da Matemática nos permite conhecer seu objeto, bem como "compreender o lugar dessa ciência na atividade produtiva e social dos homens" (Ríbnikov, 1987, p. 12).

A prática nos ensina que toda ordem lógica de qualquer ciência, sua estrutura, interrelação e inclusive a existência de ramos independentes não constituem algo imutável. Elas são fruto do desenvolvimento histórico. $\mathrm{O}$ desenvolvimento histórico das ideias sobre uma ciência não é outra coisa que o reflexo do processo histórico em forma consequente, abstrata e teórica. (RÍBNIKOV,1987, p. 18).

Concordamos com Miguel (1993, 1999, 2000) que considera que a história do desenvolvimento formal dos conceitos matemáticos na sala de aula não deve ser entendida como a tábua de salvação para que se aprendam os conceitos que se quer ensinar. Porém, compreender a história decorrente de certa filosofia ou a filosofia decorrente de certa história da Matemática que compõem nosso "instrumento de trabalho", é fundamental "para a nossa prática" (Pereira de Jesus, 2002, p. 01).

Entendemos que a história dos conceitos matemáticos, só tem sentido, na sala de aula, quando professores e alunos compreenderem o movimento das abstrações do pensamento que compuseram as formalizações que estudamos.

As abstrações, demonstrações e aplicações, são os principais traços característicos da Matemática e são esses traços que, ainda hoje, fundamentam nossas aulas de Matemática. Estudam־se, por exemplo, as multiplicações de números abstratos por outros. Não é muito comum estudarmos a multiplicação de número exato de pessoas por outras (ALEKSANDROV et al, 1988).

A história mostra que as abstrações que se processam no pensamento matemático auxiliam o homem a buscar métodos matemáticos universais, de forma que estes tenham a possibilidade de resolver todos ou a maioria dos problemas que planeja (RÍBNIKOV, 1987).

Os métodos matemáticos universais possuem três traços bem distintos: relações quantitativas e formas espaciais, abstraindo-as de todas as demais 
propriedades dos objetos; sucessão de graus de abstração crescente, como exemplo, as noções fundamentais de número e figura e o movimento quase por completo no campo dos conceitos abstratos e suas inter-relações (ALEKSANDROV et al, 1988).

Parte significativa dos métodos matemáticos universais elaborados pelas abstrações do pensamento humano em sua atividade está diretamente relacionada ao desenvolvimento dos conceitos matemáticos.

Se, desejamos estudar com certa profundidade os métodos e as abstrações do pensamento algébrico, por exemplo, construídos de forma lógico-histórica no pensamento, faz-se necessário considerar que, em substância, não há nenhum cientista que trabalhe criativamente sem se dedicar à história de sua ciência (RÍBNIKOV, 1987).

Nesse sentido, ao defender que o ensino de álgebra seja criativo, de forma a permitir a professores e alunos se entenderem na realidade e no movimento da realidade, a partir da compreensão do pensamento algébrico enquanto descrição de movimentos, estamos acenando que o movimento lógico-histórico da álgebra faça parte da organização do ensino, tanto da Educação Básica, quanto dos cursos de licenciatura de Matemática, a partir de situações desencadeadoras de aprendizagem que considerem os nexos conceituais dos conteúdos.

Isso quer dizer que, concordamos com Radford (2011) quando afirma que:

A história da Matemática pode nos dar uma nova perspectiva sobre o ensino. Obviamente, não estamos dizendo que nossos alunos têm que seguir o mesmo caminho que aqueles dos matemáticos antigos. Em vez disso, é uma questão de compreender melhor a natureza do conhecimento matemático e de encontrar, dentro de sua estrutura histórica, novas possibilidades de ensino. (RADFORD, 2011, p. 44).

Defendemos ainda, juntamente com o mesmo autor que:

Vale a pena enfatizar o papel que a pesquisa histórica pode exercer em programas de formação e formação continuada de professores. De fato, na maior parte do tempo, as concepções dos professores acerca do conteúdo matemático que eles ensinam decorrem da formulação matemática contemporânea (...). No entanto, a formulação contemporânea é o resultado de um longo processo de mudanças e transformações conceituais e não necessariamente é o melhor ponto de partida para os alunos. Entretanto, na falta de outras alternativas, a formulação 
contemporânea torna-se uma camisa de força na escolha de conteúdo a ser ensinado, em sua organização, e em sua articulação com outros conhecimentos. (RADFORD, 2011, p. 16).

Ao acenarmos, como alternativa à didática tradicional, o movimento dialético lógico-histórico, estamos compartilhando dos estudos de Moisés (1999) que defende a relação lógico-histórica na prática pedagógica do professor, uma vez que tal relação "se configura, (...) no centro da ação pedagógica comprometida com a dinâmica que combina as dimensões do relacionamento humano do indivíduo/particular até o coletivo/geral” (MOISÉS, 1999, p. 68).

Estamos defendendo que, as situações desencadeadoras de aprendizagem considerem: a) o movimento histórico do conceito, ou seja, o lógico-histórico do conceito que está sendo estudado; b) os momentos dialéticos de sua formação e c) a vivência na participação dos sujeitos vinculada a um processo reflexivo-ativoexplicativo, dimensionado pela dinâmica relacional indivíduo-grupo-classe, considerando-se que:

$\mathrm{Na}$ Atividade Orientadora de Ensino as necessidades, motivos, objetivos, ações e operações do professor e dos estudantes se mobilizam inicialmente por meio da situação desencadeadora de aprendizagem. Esta é organizada pelo professor a partir dos seus objetivos de ensino que, como dissemos, se traduzem em conteúdos a serem apropriados pelos estudantes no espaço de aprendizagem. As ações do professor serão organizadas inicialmente visando colocar em movimento a construção da solução da situação desencadeadora de aprendizagem. Essas ações, por sua vez, ao serem desencadeadas, considerarão as condições objetivas para o desenvolvimento da atividade: as condições materiais que permitem a escolha dos recursos metodológicos, os sujeitos cognoscentes, a complexidade do conteúdo em estudo e o contexto cultural que emoldura os sujeitos e permite as interações sócioafetivas no desenvolvimento das ações que visam o objetivo da atividade - a apropriação de certo conteúdo e do modo geral de ação de aprendizagem. Em outras palavras, os sujeitos, mobilizados a partir da situação desencadeadora, interagem com os outros segundo as suas potencialidades e visam chegar a outro nível de compreensão do conceito em movimento. Além disso, o modo de ir se aproximando do conceito também vai dotando-o de uma qualidade nova ao ter que resolver problemas, pois, além de ter aprendido um conteúdo novo, também adquiriu um modo de se apropriar de conteúdos de um modo geral. A situação desencadeadora de aprendizagem deve contemplar a gênese do conceito, ou seja, a sua essência; ela deve explicitar a necessidade que levou a humanidade à construção do referido conceito, como foram aparecendo os problemas e as necessidades humanas em 
determinada atividade e como os homens foram elaborando as soluções ou sínteses no seu movimento lógico-histórico (MOURA et al, 2010, p. 222-3).

As ideias que estamos apresentando, bem como, os elementos teóricos que fundamentam o movimento lógico-histórico e, consequentemente, as situações desencadeadoras de aprendizagem foram estudadas por mais de 40 pessoas, entre licenciandos e professores da Educação Básica, das áreas de Física e Matemática, dos quais, 36 foram bolsistas e 04 voluntários, durante o desenvolvimento da investigação: Produtos Educacionais no Mestrado Profissional em ensino de Física e Matemática: itinerários de desenvolvimento, implementação e avaliação, a partir da rede de pesquisa participante escola-universidade, no OBEDUC/UFSCar.

Os pressupostos teóricos que conduziram as ideias centrais da investigação foram: 1) o professor deve ser considerado como profissional crítico-reflexivo que toma decisões sobre o currículo; 2) o trabalho em equipe na escola deve ser considerado para que possa haver a consolidação do trabalho e da inovação pedagógicos; 3) a formação de redes de investigação participantes é necessária, para que se possa almejar a melhoria do ensino, a partir do desenvolvimento de pesquisas com os professores sobre e na escola.

A investigação considerou pelo menos dois aspectos que se fundamentam na pesquisa participante: negociação e diálogo, os quais permitiram com que a equipe, a cada encontro, reafirmasse o compromisso com a profissionalização do professor e com a produção de conhecimentos pedagógicos que dialogam com as problemáticas presentes nas práticas educativas, tanto dos licenciandos, quanto dos professores que atuam nas salas de aula. Tais problemáticas, bem como os estudos que ocorreram sistematicamente nos grupos de estudos e de pesquisa acolheram "diferentes vozes" e procuraram "o diálogo com saberes advindos da experiência de viver [...]" de cada um dos envolvidos, conforme apontam os estudos de Schmid (2006: p. 28).

Pode-se afirmar que, um dos aspectos importantes da pesquisa participante, o diálogo foi estabelecido entre pessoas com culturas escolares e 
acadêmicas distintas, as quais procuraram colaborar, sistematicamente, a partir de reflexões que envolviam, especialmente, o ensino de Matemática.

Outro aspecto da pesquisa participante que se apresentou na investigação está relacionado às "diferentes formas de divulgação dos trabalhos", os quais "apontam, também, na direção de uma democratização do conhecimento, abrindo a possibilidade de colaborações diferenciadas na produção de textos com diferentes linguagens e destinatários ou de outros objetos culturais [...]" (SCHMIDT, 2006, p. 29).

Neste sentido, quando as pesquisas dos licenciandos e professores da Educação Básica são divulgadas nos diversos eventos acadêmicos, bem como, nos artigos, está se democratizando e se compartilhando conhecimentos com outros profissionais que atuam nas escolas e nas universidades brasileiras. Ou seja, desde 2009, começamos a tecer redes compartilhadas de investigação que pretendem ser permanentes. Dessa forma, os estudos das problemáticas referentes ao ensino de Matemática contam com as colaborações diferenciadas dos profissionais de ensino.

Com o intuito de exemplificar como professores da Educação Básica, no contexto do OBEDUC/UFSCar interpretaram e desenvolveram situações desencadeadoras de aprendizagens, que consideram o movimento lógico-histórico dos conceitos matemáticos, em suas salas de aula, no próximo item apresentaremos as ideias centrais da Dissertação de Mestrado de Borges (2011), defendida no âmbito do Mestrado Profissional, da UFSCar.

\section{0 movimento lógico-histórico em situações de aprendizagens sobre o conceito de função}

Borges (2011, p. 07), uma das professoras da Educação Básica que estudou o movimento lógico-histórico do conceito de função, bem como as situações de aprendizagens que temos proposto $(2004 ; 2009)$, ao desenvolver sua investigação, de cunho qualitativo, conduzida pela questão: "quais são as ideias algébricas explicitadas por estudantes da EJA quando vivenciam, em um espaço não formal, situações-problema?” elaborou e desenvolveu quatro situações de aprendizagem, 
de cunho interdisciplinar, as quais foram denominadas de situações-problema: 1)

Cálculo da porcentagem de anúncios publicitários em uma revista de grande circulação nacional; 2) Número de ouro; 3) Como medir a altura da casa usando uma trena e sem usar escada e 4) Pesquisa e resenha sobre o entendimento de função. Afirma que usou:

$\mathrm{Na}$ situação 1, como ponto de partida para o ensino de Álgebra, o conceito de razão e proporção, mais especificamente, o de porcentagem e o da regra de três. (...) esses conceitos fazem parte das situações-problema apresentadas aos estudantes da EJA pelas disciplinas de Física, Química e Biologia. Já a situação-problema 2 , tem como foco condutor o entendimento de um número, até então desconhecido pelos estudantes (número áureo), visto durante uma aula sobre Arte. Sua relação com a Álgebra vem do fato de esse número poder originar-se de uma equação de segundo grau específica, que explicita certo "movimento" da realidade artística. Esse procedimento contraria o que ocorre, normalmente, com o ensino de equação do segundo grau, nas escolas. Geralmente, autores de livros didáticos apresentam o conceito de equação de segundo grau sem relacioná-lo com nenhuma área do conhecimento. Apresenta-se uma equação de segundo grau, descontextualizada, explica-se como o estudante deve resolvê-la, obtendo-se as raízes, e, em seguida, explica-se o significado dos números encontrados. Nem sempre esses números estão relacionados a algum conceito de outra área de conhecimento, como, por exemplo, à Arte, ou, ainda, ao número áureo. A terceira situação criada tem como eixo condutor o conceito de semelhança de triângulos e Teorema de Tales. (...). Já a última situaçãoproblema tem como fio condutor as ideias que fundamentam o conceito de função. A dinâmica difere das aulas tradicionais principalmente pela metodologia dialógica utilizada nas aulas. Geralmente, o conceito de função é definido, nos livros didáticos, a partir de exercícios que envolvem a Teoria dos Conjuntos. Os livros convidam os estudantes a resolverem exercícios que envolvem a correspondência entre elementos de um conjunto, ilustrado por diagramas de flechas, que "levam" um elemento de um conjunto em um elemento do outro conjunto. No âmbito desta pesquisa, a última situação-problema foi contextualizada, de forma que os estudantes puderam construir, por meio da situação proposta, a noção de dependência entre grandezas, observando que as variações em uma grandeza refletiam na outra, obedecendo a um padrão, conforme indica-nos os estudos de Caraça (1951) (BORGES, 2011, p. 48-49).

Segue excertos de diálogos ocorridos na sala de aula de Borges (2011), enquanto interagia com as alunas da EJA: Ta, $\mathrm{Pa}$ e $\mathrm{He}$, na aula de função; 
enquanto desenvolvia a situação 4 intitulada: Pesquisa e resenha sobre o entendimento de função.

Figura 1 - Excertos de diálogos ocorridos na sala de aula.

Situação-problema 4: Pesquisa e resenha sobre o entendimento de função

Objetivo: analisar e discutir o material produzido pelos estudantes sobre o entendimento de cada um a respeito do conceito de função.

Descrição das aulas: A atividade ocorreu em dois momentos. O primeiro aconteceu em um sábado, dia 22 de maio, antes do início da reunião, quando $T a$ veio tirar dúvidas. (...) Ela estava fazendo exercícios sobre função. Em seu caderno, havia muitos cálculos (feitos) do tipo: "dado $f(x)=$ (uma expressão de primeiro ou segundo grau), calcule $\mathrm{f}(3), \mathrm{f}(1 / 2)$ etc". A dificuldade dela, na verdade, era calcular $f$ de números decimais(...) Percebemos que era um exercício totalmente mecânico para ela, pois perguntamos: "e a definição de função, depois de tanto exercício, você conseguiu fazer?" Ela respondeu: "não, isso ainda está meio obscuro. (...). Na quarta-feira, dia 26 de maio (...), os estudantes vieram tirar dúvida a respeito da tarefa que havíamos deixado: "Explique o que é função e dê exemplos". $P a$ diz: "Ai, eu pensei assim, vê se está certo: se eu for fazer uma caminhada pelo quarteirão..." Nós [Profa.]: "Ok, o que há de função nisso? A caminhada por si é uma função?". Pa: "Não só a caminhada, (...), os minutos que eu vou gastar se eu andar 1, 2, 3 ou 4 quarteirões. Tá certo?". Nós [Profa.]: "Sim, mas por que está certo? Você consegue explicar?". Pa: "Porque está envolvendo os minutos junto com o que eu vou andar". Nós [Profa.]: "Então, você consegue dizer quais as variáveis envolvidas?". $\mathrm{Pa}$ [Profa.]: "distância e tempo" (...). He: "Depois de domingo, eu fico querendo pensar em função. Hoje mesmo, na aula que o (...) estava dando, teve uma hora que ele falou uma coisa sobre pressão que eu vi função ali". Nós [Profa.]: "Em que hora? O que o (...) falou?" (...). He: "A aula foi sobre pressão; enquanto ele explicava, eu consegui enxergar função naquilo!" (...) "Explica isso com calma". He: "Porque assim, a pessoa vai no fundo do mar, certo? A profundidade vai aumentando e a pressão também. Porque se muda um, muda o outro. Não sei se estou sendo clara". Nós [Profa.]: "Está sendo clara, sim, tente relacionar com o que vocês pesquisaram". He: "É que nunca vai ter valor igual, tipo nesse exemplo que eu te entreguei, da telefonia, ou do táxi que a gente assistiu. Nunca vai ter o mesmo preço para corridas diferentes, nem pressão igual pra profundidades diferentes. Nesse que eu escrevi, da telefonia, não tem como um usar mais que o outro e pagar a mesma coisa de telefone." Nós [Profa.]: "Isso é relevante? Qual a importância disso pra função em si?". He: "Muito! Pelo que eu estudei, nem sei se tá certo, mas é o essencial da função. Eu gostei muito, porque antes (do vídeo e da aula do ...) eu estava com raiva, sem conseguir entender." Pa: “(...) Eu também adorei. Adorei aprender, nunca imaginei que conseguiria entender essa coisa depois do tanto que estudei. Tem coisa que eu entendia tudo errado, por exemplo, quando falava constante, eu achava que era uma coisa que ia e nunca parava, mas não é isso, nossa, é o contrário, quando fala constante, significa que é fixo. Outra coisa que aprendi!" (Borges, 2011 p. 73-76).

Fonte: Borges (2011).

Ao analisar as aulas que desenvolveu, a partir das quatro situações de aprendizagem que elaborou, Borges (2011) afirmou:

Assim, podemos continuar defendendo que é possível aos professores criarem suas próprias atividades, considerando-se o movimento da sala de aula (...). Ao mesmo tempo, no movimento dialógico, o estudante pode ser considerado co-autor das situações pensadas pelos professores, a partir das demandas da sala de aula. Há de se ressaltar a importância desse tipo de movimento na sala 
de aula, porque permite que os estudantes se coloquem à frente das situações desafiadoras, que instigam sua curiosidade, permite que cada um coloque em jogo seus conhecimentos e permite que esses saberes sejam transformados em conhecimento. As situações-problema que criamos diferenciam-se das propostas do atual currículo (...) porque não reproduzem a lógica de ensinar primeiro a teoria e depois aplicá-la de alguma maneira (seja em uma relação de exercícios mecânicos, ou em uma situaçãoproblema). E possuem os seguintes aspectos comuns: permitem que os estudantes façam generalizações (porém, de maneiras bem distintas), que busquem regularidades e formulem hipóteses que podem ou não serem validadas. Talvez as atividades que elaboramos sejam mais apropriadas para estudantes Jovens e Adultos porque convidam esses estudantes a uma reflexão e a uma busca constante de soluções que indiquem as ideias que têm sobre os conteúdos que lhes fazem sentido em cada situação-problema. É como se, no âmbito da Educação não formal, os estudantes Jovens e Adultos ficassem mais livres e autônomos para, de alguma forma, explicitar a si mesmos, os conceitos que aprenderam, a partir das situações-problema apresentadas. Podemos afirmar que não podemos propor, (..), aulas dissociadas da realidade dos estudantes. Não há como ter, como ponto de partida e chegada, apenas as fórmulas matemáticas, como, por exemplo, escrever na lousa que "uma função polinomial de $1^{\circ}$ grau é do tipo $y=a x+b \ldots$... Para esse grupo, essa linguagem não fez sentido durante toda a escolaridade e continuaria não fazendo. (BORGES, 2011, p. 82-83).

Ao interpretarmos os excertos acima, podemos afirmar que, a organização do ensino de Matemática feita por Borges (2011), em sua sala de aula, considerou os pressupostos da Atividade Orientadora de Ensino (AOE), uma vez que, representou unidade indissociável entre ensino e aprendizagem, considerando-se que:

$\mathrm{Na}$ AOE, ambos, professor e estudante, são sujeitos em atividade e como sujeitos se constituem indivíduos portadores de conhecimento, valores e afetividade, que estarão presentes no modo como realizarão as ações que têm por objetivo um conhecimento de qualidade nova. (MOURA, 2010, p. 97).

Aqui, o conhecimento de qualidade nova para os alunos esteve relacionado ao pensamento teórico dialético de conteúdos matemáticos, artísticos e históricos. No caso da professora, além destes conhecimentos, pôde conhecer e vivenciar uma nova proposta de ensino que lhe permitiu conduzir, de forma diferenciada, a sua sala de aula. 


\section{Considerações finais}

Ao propormos que o movimento lógico-histórico seja considerado perspectiva didática para o ensino de Matemática, chamamos a atenção para o fato de que é possível romper com a didática tradicional que frequenta as nossas escolas e, consequentemente, com uma organização do ensino de Matemática que desconsidera, que ignora a história dos conceitos matemáticos.

Dessa forma, os professores podem elaborar e desenvolver situações desencadeadoras de aprendizagem, que tenham como ponto de partida em suas aulas, os nexos conceituais, com ênfase nos nexos internos que compõem os conceitos que ensinam, rompendo com a atual "formulação matemática contemporânea do conteúdo" (RADFORD, 2011, p. 16) que se pauta no treinamento dos conceitos, a qual indica como ponto de partida e de chegada das aulas de Matemática, o último estágio de rigor dos conceitos definido, historicamente, no século XX.

\section{Referências}

ALEKSANDROV, A.D. et al. La matemática: su contenido, métodos y significado. Madrid, Alianza Editorial, 1988. 1232 p.

BOHM, D. A totalidade e a ordem implicada. São Paulo/SP, 12.ed. Cultrix, 1980. $222 \mathrm{p}$.

BORGES, A. A. A. G. Ideias algébricas explicitadas por estudantes da EJA em espaços nãoformais: o caso do cursinho de Ribeirão Preto. 2011. 108 f. Dissertação (Mestrado em Educação) - Centro de Ciências Exatas, UFSCar, São Paulo, 2011.

CARAÇA, B.J. Conceitos fundamentais da matemática. 2. ed. Lisboa: Gradiva, 1998. $318 \mathrm{p}$.

DAVYDOV, V. V. Tipos de generalización en la enseñanza. La Havana, Cuba: Editorial Pueblo y Educación, 1982. 488 p.

FERNÁNDEZ, F.A. Didáctica! Que didáctica? In: FERNÁNDEZ, F.A. ET AL. Didáctica: teoria y práctica. Habana: Editorial Pueblo y Educacion, 2007, p. 0120. 
KOPNIN, P. V. A dialética como lógica e teoria do conhecimento. Rio de Janeiro, RJ: Civilização Brasileira, 1978. Coleção Perspectivas do homem. V. 123. 353 p.

KOSIK, K. Dialética do concreto. Rio de Janeiro/RJ. Editora Paz e Terra, 7.ed. 2002. $228 \mathrm{p}$.

LIBÂNEO, J.C. A didática e a aprendizagem do pensar e do aprender: a Teoria Histórico-cultural da Atividade e a contribuição de Vasili Davydov. Revista Brasileira de Educação. Set /Out/Nov /Dez 2004 No. 27, p. 5-27.

LIMA, L. C. Da mecânica do pensamento ao pensamento emancipado da mecânica. In: Programa Integrar. Caderno do Professor: trabalho e tecnologia. CUT/SP, 1998, p. 95-103.

MIGUEL, A. Três estudos sobre História e educação Matemática. 1993. 361f. Tese (Doutorado em Educação). Faculdade de Educação, UNICAMP/SP, 1993.

Uma investigação acerca de algumas formas de se conceber o papel da História da Matemática na pesquisa contemporânea em Educação Matemática. Faculdade de Educação, UNICAMP/SP, Relatório de pesquisa desenvolvido em período de semestre sabático, julho a dezembro de 1999.

Educação Matemática e Epistemologia. Faculdade de Educação, UNICAMP/SP, mimeo, 2000.

MOISÉS, R. P. - A resolução de problemas na perspectiva histórico/lógica: o problema em movimento. 1999. 104f. Dissertação (Mestrado em Educação). Faculdade de Educação. USP/SP, 1999.

MOURA, M.O. (Org). A atividade pedagógica na teoria histórico-cultural. São Paulo: Liber, 2010. 178 p.

MOURA, M.O., ARAÚJO, E.S., MORETTI, V.D., PANOSSIAN, M.L., RIBEIRO, F.D. Atividade Orientadora de Ensino: unidade entre em sino e aprendizagem. Revista Diálogo Educacional, Curitiba, v. 10, n. 29, p. 205-229, jan./abr. 2010.

PEREIRA DE JESUS, W. Educação Matemática e Filosofias sociais da matemática: um exame das perspectivas de Ludwig Wittgenstein, Imre Lakatos e Paul Ernest. 2002. 171 f. Tese (Doutorado em Educação). Faculdade de Educação - UNICAMP, 2002.

RADFORD, L. Cognição Matemática: História, Antropologia e Epistemologia. Sociedade Brasileira de História da Matemática. São Paulo. Editora Livraria da Física, 2011. 342 p.

RENSHAW, P. D. A teoria sociocultural de ensino-aprendizagem: implicações 
para o currículo no contexto australiano. In Cadernos pedagógicos, no. 18, Secretaria Municipal de Educação de Porto Alegre, 1999.

RÍBNIKOV, K. Historia de las matemáticas. Editorial Mir Moscú, 1987. 488 p.

SOUSA, M.C. O ensino de álgebra numa perspectiva lógico-histórica: um estudo das elaborações correlatas de professores do Ensino Fundamental. 2004. 278 f. Tese (Doutorado em Educação). Faculdade de Educação - UNICAMP, 2004.

Quando professores têm a oportunidade de elaborar atividades de ensino de Matemática na perspectiva lógico-histórica. Bolema, Rio Claro (SP), Ano 22, n ${ }^{\circ} 32$, p. 83 a 99, 2009.

Recebido em abril de 2017. Aprovado em dezembro de 2017. 